\section{SRC Members}

THE Science Research Council bas announced the appointment of six new members to its research boards so as to make up for the regular retirement of previous members. On the Astronomy Space and Radio Board, Professor J. Ring (Imperial College, London) and $\mathrm{Mr} \mathrm{M}$. $\mathrm{O}$. Robins (Ministry of Aviation Supply) replace $\mathrm{Mr}$ R. Lees (Ministry of Aviation Supply) and Professor P. A. Sheppard (Imperial College, London). On the Engineering Board, Professor G. D. S. MacLellan (University of Leicester), Professor R. J. A. Paul (University College of North Wales) and Professor R. W. H. Sargent (Imperial College, London) replace Professor J. G. Ball (Imperial College, London), $\mathrm{Mr}$ H. R. Galleymore (Procter \& Gamble Limited) and Dr M. R. Gavin (Chelsea College of Science and Technology). On the Nuclear Physics Board, Professor R. G. Chambers (University of Bristol), Professor L. L. Green (University of Liverpool) and Dr K. F. Riley (University of Cambridge) replace Professor W. E. Burcham (University of Birmingham), Sir Derman Christopherson (University of Durham) and Dr K. Mather (University of Southampton). Dr T. Emmerson (Guest, Keen and Nettlefolds Limited) and Professor Sir Ronald Nyholm (University College, London) have retired from the Science Board but no new appointments have been made.

actors is expected to be determined almost entirely by comparisons with the fast breeder reactor during development and the installed capacity will not increase at all once the fast breeder reactor becomes established.

\section{METEOROLOGY}

\section{Come in Pleuse, No. 24}

A WEATHER satellite that obtains its data not from cameras but by the interrogation of automatic sensors carried into the atmosphere by balloons is to be launched next week. The balloons will take the sensors into a region which, because of its remoteness, is terra incognita on weather maps - the oceans of the southern hemisphere.

Although the satellite is experimental in the sense that the electronic system to be used for collecting data has not been applied before, the experiment is on a sufficiently large scale to make a significant contribution to the World Weather Programme. Five hundred

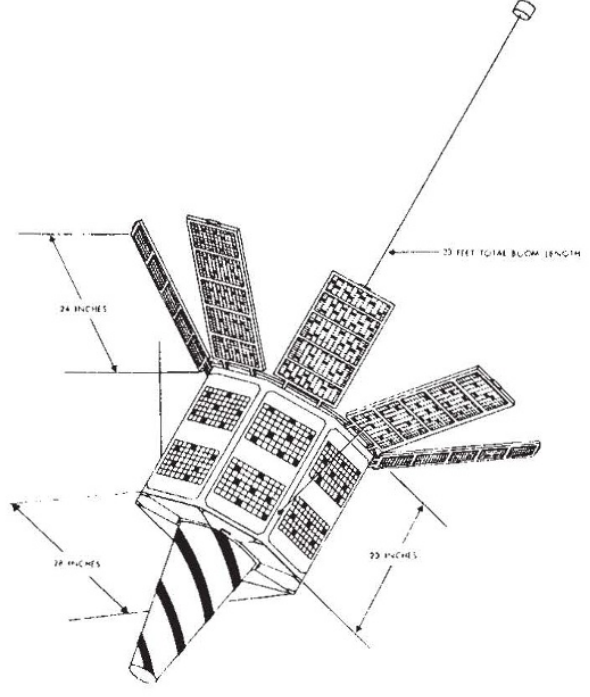

The French Eole weather satellite. The long boom is the gravity gradient stabilization system, so that the conical spiral antenna for balloon interrogation and data collection points towards the Earth.

sensors and balloons are available for launch from three locations in Argentina at latitudes of $33^{\circ}, 39^{\circ}$, and $55^{\circ} \mathrm{S}$ by the French Centre Nationale d'Etudes Spatiales, which also developed the satellite to be launched on or after August 16 by NASA.

In previous trials, balloons launched from southern hemisphere stations have lasted for several months, circumnavigating the Earth several times until lost because of icing. The French satellite carries a 4 Watt, $464 \mathrm{MHz}$ transmitter for the interrogation of the balloonborne sensors, a receiver for collecting the data transmitted by the sensors, and a $136 \mathrm{MHz}$ transmitter for relaying the data to ground stations.

The philosophy of the experiment seems to be the recognition that in spite of the impact that pictures of cloud cover from conventional weather satellites have had on weather analysis and forecasting, there is still an urgent need for more measurements of temperature, pressure and wind speed which ground stations provide. In the absence of a technique that allows pressures and wind speeds in the lower atmosphere to be measured directly from sensors on satellites, the approach being tried by CNES and NASA is the most promising way of obtaining data from remote areas that are of meteorological interest.

Although the techniques of communications satellites have been used before for the collection of data from automatic sensors, the French system is an important advance on earlier American experiments because of its large capacity, allowing the tracking of as many as 500 balloons. It will be possible to determine the horizontal location of the balloons to the nearest $3 \mathrm{~km}$ (their vertical position will be governed by their inflation pressure so that they float at $11.85 \mathrm{~km}$ ), a considerable improvement on a similar data collection system that has been tested on the Nimbus satellites and better by far than tracking from the ground.

\section{EASTERN SCIENCE \\ Comecon Looks Ahead}

from our Soviet Correspondent

THE new "complex programme" of economic integration of the COMECON countries, promulgated by the 25 th session of COMECON, raises some interesting questions about the future of science and technology in eastern Europe. This programme, which will be implemented during the next 15-20 years, is aimed at the "further deepening and improvement of economic cooperation and the development of the socialist economic integration of the member countries of COMECON" by measures including a "collective currency policy", the sharing of research and development experience between the member countries, a common policy of external trade, and a coordinated plan for basic research and industry. This, however, is to be accomplished on a basis of "respect for national sovereignty, independence and national interests, non-interference in the internal affairs of member countries, complete equality of rights, mutual advantage and comradely cooperation". The programme will be based on "multilateral and bilateral mutual consultations", and will not be accompanied by the creation of new "supranational bodies".

This stress on national autonomy within COMECON seems to have been largely at the insistence of the Romanian delegation, which has been active in resisting what would appear to be the logical outcome of COM$\mathrm{ECON}$ - virtual integration of the eastern bloc with the Soviet Union. But it seems unlikely that this view will stand up against the implicit supranational nature of the projects proposed by the programme. These include, in particular, the "planned expansion of international specialization and cooperation in industry, science and technology", the end result of which, whether decided by a supranational body, or by "direct links between the ministries and other state organs concerned", will be, to some extent, a curtailment of national autonomy as far as the choice of project is concerned.

A large section of the programme deals specifically with cooperation in science and technology. The emphasis here is on matters of policy, such as the planning and solution of important scientific and technical prob- 